\title{
Real Options Analysis and the Assumptions of Corporate Finance: A Non-Technical Review*
}

\author{
Tom Arnold \\ University of Richmond, USA \\ Richard L. Shockley, Jr. \\ Indiana University, USA
}

This paper provides a non-technical presentation of the theoretical foundations of corporate financial decision making and the net present value (NPV) rule. Our objective is to show that the concepts of value and value creation arise from a single, unified framework that is firmly rooted in neoclassical microeconomic theory. This, in turn, allow us to demonstrate that the corporate valuation approach generically known as real options analysis is perfectly justifiable - without further qualification - in any situation when investors want managers to maximize NPV.

Key words: NPV, real options analysis, arbitrage, fundamental theorem of asset pricing

\section{Introduction}

This paper provides a non-technical presentation of the theoretical foundations of corporate financial decision making and the net present value $(N P V)$ rule. Our objective is to show that the concepts of value and value creation arise from a single, unified framework that is firmly rooted in neoclassical microeconomic theory. This, in turn, allow us to demonstrate that the corporate valuation approach generically known as real options analysis is perfectly justifiable - without further

\footnotetext{
* The authors thank Mike Ferguson, Scott Smart, and an anonymous referee for very helpful comments.
}

(Multinational Finance Journal, 2010, vol. 14, no. 1/2, pp. 29-71)

(C) Multinational Finance Society, a nonprofit corporation. All rights reserved. DOI: $10.17578 / 14-1 / 2-2$ 
qualification - in any situation when investors want managers to maximize $N P V$.

A common objection to real options analysis is that option pricing models require certain assumptions that are not met in real asset markets. For example, one often hears the ritual protest that options on real assets cannot be priced because the real asset is not traded, and hence cannot be held in a "tracking portfolio". We'll show that this objection is completely unfounded in any situation where discounted cash flow $(D C F)$ can be applied: as long as a manager is willing to make the assumptions necessary for valuation of an illiquid asset using $D C F$, then the manager has already made assumptions that are sufficiently strong to price options on that asset even though the real asset itself is not traded.

To put it another way, rejection of real options analysis in a corporate setting based on the illiquidity of the project implies rejection of $D C F$ for valuation of that project as well. $D C F$ and real options analysis are simply two alternative (but theoretically equivalent) mechanical approaches to valuation of a corporate asset.

But the story is even deeper. In spite of what many practitioners and academics believe, the $N P V$ rule for corporate decision-making is not an axiom or fundamental truth, but rather is the result of an economic construction that relies on several critical assumptions. As it turns out, the assumptions required for the appropriateness of both $D C F$ and real options analysis are necessary conditions for the $N P V$ rule to be the appropriate managerial benchmark. In other words, rejection of real options analysis in a corporate setting based on the illiquidity of the project implies rejection of $N P V$ as the manager's guiding principle. ${ }^{1}$

As the reader will soon see, our review will require a synthesis of two streams of finance theory literature. The first is the modern theory of asset pricing, which stems directly from the neoclassical portfolio choice problem. This body of theory gives us the framework for the mechanics of valuation in financial markets. The second, which is known as the "unanimity" literature, examines the objectives of corporate managers who make real asset decisions on the behalf of their investors. This body of theory tells us the conditions under which the investors want the managers to use financial market valuation mechanics in order to evaluate new opportunities (that is, the standard

1. On the other hand, the conditions required for maximization of $N P V$ to be the desired goal of management are sufficient conditions for both $D C F$ and option pricing to be appropriate valuation techniques. So acceptance of the $N P V$ rule (as usually defined) is, by logical force, acceptance of the appropriateness of real options analysis. 
$N P V$ rule).

We'll actually tackle these in reverse order, but first we will need to supply some foundational material. Section II presents some basic definitions and a key result that provides the common motif known as linear pricing. Then, in Section III, we proffer a general summary of corporate finance and capital budgeting. The main point of Section III is a clear statement of the unanimity result - the conditions under which the appropriate goal of management is maximization of shareholder value. The notion of shareholder value requires an understanding of valuation in the capital markets, and we turn to this issue in Section IV. In this part of the paper, we provide an extended (though straightforward) example of linear pricing and we lay bare some of the simplifying shortcuts we usually take in the classroom. Only when the big shortcuts are removed can we show that $D C F$ and real options valuation are really the same - they are both applications of the linear pricing result. We then demonstrate, for the interested academic reader, that one can express the linear pricing approach in several different (but absolutely equivalent) ways. Section $\mathrm{V}$ concludes the paper with a summary.

\section{Fundamentals}

Economists describe a risky world as one in which there are many possible future states of nature. A state of nature is a particular possible future realization of aggregate consumption at a particular point in time; that is, it is a potential macroeconomic outcome. ${ }^{2}$ For teaching purposes, it is useful to simplify things by assuming that there are a small number of future states at only one future point in time; the intuition carries over easily to a large number of states at many future points in time. So for example, consider a world where there are only two macroeconomic outcomes that can possibly occur one year from today: the economy booms, or the economy busts. The "boom" and "bust" economies are the two future states of nature, one of which will actually occur.

A useful abstraction is to consider units of consumption (or equivalently "cash flow") in different states of nature at various future points in time to be different goods. In other words, a unit of consumption (or cash flow) in the boom state is a different good from

2. The results we describe require the state space to be of finite dimension. 
a unit of consumption (or cash flow) in the bust state.

A security is a financial asset completely characterized by its future state-contingent cash flows. For example, consider the securities X, Y and $\mathrm{Z}$ whose current prices and future state-contingent cash flows we present in the table below.

\begin{tabular}{|cccccc|}
\hline & & $\underline{4}$ & $\underline{Y}$ & $\underline{Z}$ \\
& & Current Prices: & 10 & 9 & $?$ \\
& & State-Contingent Cash Flows \\
Subj.Prob. & Future Macro State & $\underline{X}$ & $\underline{Y}$ & $\underline{Z}$ \\
0.5 & Boom & 20 & 10 & 30 \\
0.5 & Bust & 5 & 10 & 0 \\
\hline
\end{tabular}

Securities $\mathrm{X}$ and $\mathrm{Z}$ are risky financial assets, because each has future cash flows that vary across macroeconomic states. Security Y, on the other hand, is riskless. The cash flows on the securities come from real assets, which are the economy's primitive assets (be they tangible or intangible). Securities are claims on the cash flows of real assets (in one way or another), and the financial market is the hypothetical "place" where these securities trade. Individual agents select their securities for investment by solving the portfolio choice problem.

Portfolio Choice Problem: choose portfolio holdings of securities and levels of current and future state-contingent consumption to maximize utility of consumption, subject to two conditions: (1) that the state-contingent portfolio payoffs achieved by the portfolio holdings equal the desired state-contingent consumption levels, and (2) that current consumption plus current investment in securities equals current endowment (or wealth).

The portfolio problem's general results we utilize in this paper are called preference free, which means that they do not rely on any specific assumptions about our agents' utility of consumption (except that all agents prefer more to less). When we get to our examples later in the paper, we will impose further restrictions on utility; however, we wish to assure the reader that these specifications will be inconsequential to the general results.

The single concept that unifies all of finance is the notion of an 
arbitrage opportunity. An arbitrage opportunity is a portfolio change that would make all agents who prefer more to less strictly better off. While there are many taxonomies of arbitrage opportunities, they all involve simultaneous purchase and short sale of securities such that the arbitrageur achieves positive returns with no risk whatsoever to his or her endowment. ${ }^{3}$

Absence of arbitrage is a critical feature of an extremely important result in finance - a result so fundamental, in fact, that it is called the Fundamental Theorem of Asset Pricing.

Fundamental Theorem of Asset Pricing: ${ }^{4}$ The following conditions are equivalent:

(1) There exists at least one agent in the economy who prefers more to less and who has an optimum solution to the portfolio choice problem.

(2) The financial market provides no arbitrage opportunities.

(3) There exists a positive linear pricing rule which correctly values all financial market assets.

The term "positive linear pricing rule" is a somewhat abstract construct that we'll pin down more carefully in section IV. However, we can say at this juncture that the positive linear pricing rule is just a valuation concept that can be expressed in a variety of absolutely equivalent ways - some of which are very familiar. The essential point for us is the term linear: if the future state-contingent cash flows on a security are linearly related to the future state-contingent cash flows on any other portfolio of securities, then the price of the first asset must be linearly related to the prices of the securities in the other portfolio.

If there are no arbitrage opportunities in our simplified financial market with securities $X, Y$ and $Z$, we can exploit the Fundamental Theorem to find the current market value of $Z$. Though there are many ways to do this, we'll demonstrate it with two common approaches. We'll illustrate several other approaches in section IV.

3. One example of an arbitrage opportunity would be a strategy that achieves an immediate cash inflow with no possibility of any future cash inflows or outflows; another example would be a strategy with no immediate cash inflow or outflow but with non-negative cash flows in all future states (and with strictly positive cash flow in at least one).

4. The interested reader can find an accessible proof in Dybvig and Ross $(1987,2003)$. 


\section{A. Approach \#1}

It is easy to verify that in both the "boom" and "bust" economies, the cash flow on security $Z$ is equal to two times the cash flow on security $X$ minus one times the cash flow on security $Y$; therefore, the linear relationship is $Z=2 Y-1 X$. So it must be that the current price of $Z$ equals two times the price of $X$ minus one time the price of $Y$, or $Z=2 X$ $-1 Y=2(10)-1(9)=11$. The price of $Z$ must be 11 , else there is an arbitrage opportunity: if the market price of $Z$ is less than 11 , then one can create a "free lunch" by buying $1 Z$, selling $2 X$, and buying $1 Y$; if the price of $Z$ is greater than 11 , sell $1 Z$, buy $2 X$ and sell $1 Y$. Approach \#1 illustrates what many people call a tracking portfolio approach to valuation: one can "track" an investment in $Z$ with a portfolio that is long 2 units of $X$ and short 1 unit of $Y$, so the value of $Z$ must be equal to the value of this tracking portfolio. Practitioners generally associate the tracking portfolio approach with the valuation of derivatives, and indeed this is usually the first derivatives pricing method presented to students. ${ }^{5}$

\section{B. Approach \#2}

We can also demonstrate linear pricing using rates of return. A portfolio with $w \%$ invested in security $X$ and the rest in security $Y$ earns the state-contingent return $w \cdot r_{X}+(1-w) \cdot r_{Y}$. So if there's a linear relationship between the returns on $Z$ and the returns on a portfolio of $X$ and $Y$, then it will be expressed by the following simultaneous equations:

$$
\begin{gathered}
r_{Z}(\text { Boom })=w \cdot r_{X}(\text { Boom })+(1-w) \cdot r_{Y}(\text { Boom }) \\
r_{Z}(\text { Bust })=w \cdot r_{X}(\text { Bust })+(1-w) \cdot r_{Y}(\text { Bust })
\end{gathered}
$$

Filling in what we know (or can calculate) from the table above makes the simultaneous equations look like this:

$$
\frac{30}{P_{Z}}-1=w \cdot 100 \%+(1-w) \cdot 11.11 \%
$$

5. In this case, security $Z$ could be interpreted as 3 calls on $X$ with a strike price of 10 . 


$$
\frac{0}{P_{Z}}-1=w \cdot-50 \%+(1-w) \cdot 11.11 \%
$$

These are two equations in two unknowns: $P_{Z}$ (the price of $Z$ ) and $w$. It is straightforward to solve these, and the reader can verify that $w=$ $181.82 \%$ and $P_{Z}=11$. Of course this is the same price we got in approach \#1, but you should also notice that $181.82 \%$ is the "weight" of security $X$ in the tracking portfolio from approach \#1. In fact, we could exploit this to show a more familiar approach to valuation. If the return on $Z$ in both possible states of nature is equal to 1.8182 times the return on $X$ minus 0.8182 times the return on $Y$, then the expected (or probability-weighted) return on $Z$ must be 1.8182 times the expected return on $X$ minus 0.8182 times the expected return on $Y$. Since the expected returns on $X$ and $Y$ are $25 \%$ and $11.11 \%$, respectively, then the expected return on $Z$ must be

$$
\begin{aligned}
\bar{r}_{Z} & =1.8182 \cdot \bar{r}_{X}+0.8182 \cdot \bar{r}_{Y} \\
& =1.8182 \cdot 25 \%+0.8182 \cdot 11.11 \% \\
& =36.36 \%
\end{aligned}
$$

Since the expected return on $Z$ must be $36.36 \%$, its price today must be set such that its expected value in the future is $36.36 \%$ higher, or

$$
\begin{gathered}
P_{Z}\left(1+\bar{r}_{Z}\right)=E\left\{C F_{Z}\right\} \\
P_{Z}=\frac{E\left\{C F_{Z}\right\}}{\left(1+\bar{r}_{Z}\right)}
\end{gathered}
$$

In our problem

$$
\begin{gathered}
P_{Z}=\frac{0.5 \times 30+0.5 \times 0}{1+36.36 \%}=\frac{15}{1.3636} \\
P_{Z}=11
\end{gathered}
$$

Even the novice reader will recognize this as valuation by discounted 
cash flow. The $D C F$ model is nothing more than an application of linear pricing.

It may seem to be something of a tautology, in that we had to solve for the price of $Z$ before we could find its required rate of return for the $D C F$ valuation. But this is precisely what goes on when we do $D C F$. The practical approach is to estimate the required rate of return on an asset, and then use that return in the $D C F$ model to value the asset.

To estimate required rates of return for $D C F$, we turn to what are called asset pricing models (such as the CAPM or APT). A key goal of any asset pricing model is to provide the practitioner with a way of estimating the required rate of return on a new asset without explicitly forming the tracking portfolio or solving the simultaneous return equations. Of course, models are simplifications that require assumptions, and in order to implement linear pricing via an asset pricing model we need to place restrictive conditions on the world.

The point here is that $D C F$ is absolutely equivalent in theory to "textbook" option pricing techniques, in that both are applications of linear pricing. In the next section, we explore the conditions under which a firm's investors unanimously desire that the firm's managers apply linear pricing techniques (whatever they may be) to new corporate investment opportunities.

\section{Corporate Finance, Capital Budgeting, and Unanimity}

The firm and its managers occupy a position between the real asset market (the market for new, specialized projects) and the financial asset market. Investors provide capital to firms because firms have special features that give them unique access to assets in the real asset market.

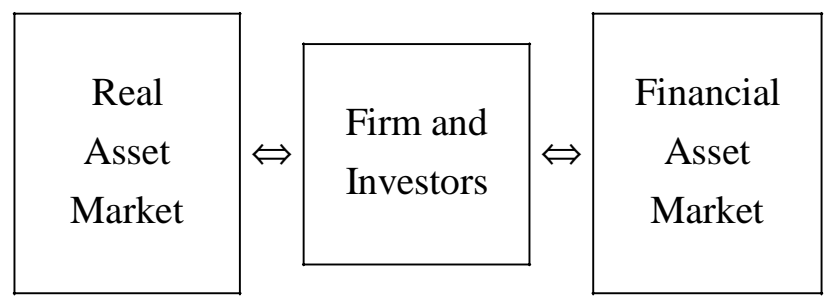

When a new corporate opportunity arises, valuation of the opportunity proceeds by asking the following question: if we adopt the (illiquid) 


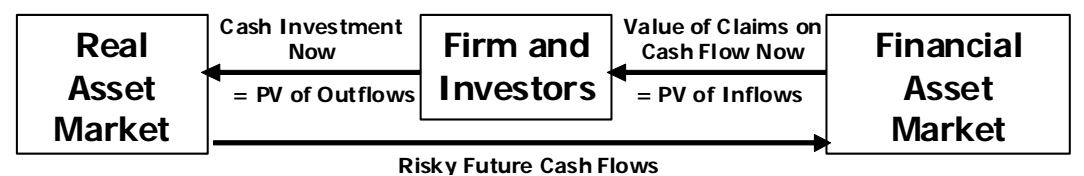

\section{FIGURE 1.}

new project and immediately sell the financial claims on the project's cash flows into the (liquid) financial markets, what price would we receive for those claims? The present value of the free cash flows from a project is actually the value that the capital markets would pay for those claims immediately. The $N P V$ is the difference between the price actually paid for the new real assets (the $P V$ of the investment) and the price that could be received in the financial market for the claims on its cash flows (the $P V$ of the inflows).

This illustrates why value grows when managers invest in positive $N P V$ projects. It also illustrates why positive $N P V$ leads to shareholder value maximization: by investing in positive $N P V$ projects, the existing shareholders capture the gain. Finally, it illustrates the procedure: we look to the financial markets to see how they currently value the risky future cash flows on a project, and compare that value to our actual cost of 'buying' the cash flows in the illiquid real asset market. ${ }^{6}$

While this is the right intuition behind corporate capital budgeting, we've left out a very important piece of information. Specifically, we have not characterized the economic situation in which shareholders actually want managers to behave this way. It is no wonder that so many people take the $N P V$ rule and shareholder wealth maximization to be axioms of finance - most finance educators (including the authors) present the procedure above as if it were handed to us by some higher authority.

The critical question is this: under what conditions do shareholders unanimously want managers to

(1) Observe the prices of existing financial assets;

6. The fact that managers don't actually sell cash flows from every new project to the financial markets is irrelevant. Using internally generated cash flow to fund a project is equivalent to selling those new cash flows to the existing equityholders, who capture the $N P V$ regardless. The existing shareholders only care that the amount invested by the firm is less than the value of the risky cash flows if they were sold to the financial markets. 
(2) Use a linear pricing approach (whatever it may be) to calculate the value of a new investment opportunity as a linear combination of existing financial market securities; and

(3) Accept those new opportunities in which the value of the new opportunity (as described in step 2) is greater than the cost of the investment (that is, opportunities that display positive $N P V$ )?

This question is the subject of what is known in finance as the unanimity literature. As it turns out, the conditions for unanimity (that is, the unanimous desire among shareholders for the $N P V$ rule) are

(A) The financial markets must be free of arbitrage opportunities. This ensures that the cash flows from the new investment opportunity would have the same value as the linear combination of traded securities that replicates (i.e., tracks) the new investment opportunity's cash flows (via the Fundamental Theorem); and

(B) Managers act as price takers. In other words, managers do not consider the effects of the new investment opportunity on the prices of financial market securities. For the new investment to have no effect on existing security prices, two conditions must be met.

(a) The financial markets must be sufficiently complete. In other words, the cash flows thrown off by the new investment opportunity must be replicable by some portfolio of traded financial securities.

(b) The new investment must not change aggregate consumption in a material way.

In the unanimity literature, the price-taking assumption is often called the competitivity assumption. Its importance should not be underestimated. If the financial market is not sufficiently complete (that is, if the cash flows from the new project are not a linear combination of the cash flows of existing securities), then the cash flow stream from the new corporate project will provide investors with previously unattainable future consumption patterns and hence potentially change their optimum portfolios. As a direct result, financial market prices 
would change and managers would not be price takers. If the new opportunity changes aggregate consumption in a material way, then its adoption will change the prices of all existing assets in the economy even if the market is complete. This happens because discount rates implicit in market prices depend crucially on the levels of current and future endowments. If a new opportunity changes future endowments, then equilibrium prices (and hence discount rates) change and managers will not be price takers.

In a nutshell, the price taking assumption requires that pre-investment financial market prices do not change due to the new investment - so managers can use the pre-investment linear pricing rule to evaluate the post-investment wealth effects of their decisions. If managers do not act as price takers, then the textbook $N P V$ rule is not what investors want managers to use. Rather, we are left with a procedure derived by Grossman and Hart (1979): managers should provide each investor with relevant information about the project; each investor should calculate their own change in utility due to the investment by forecasting what will happen to the financial market equilibrium; and managers should then weight each of these assessments by each investor's relative ownership in the firm. Needless to say, this approach is not easy to implement.

In summary, the whole procedure of corporate capital budgeting rests on figuring out what the risky cash flows of a new project are currently worth in the financial markets. Once we assume no arbitrage in financial markets and price taking by managers (which we must do in order to adopt shareholder wealth maximization as the proper goal of the firm), we can use any linear pricing approach to attach values to new, illiquid investments. $D C F$ and option pricing are equally valid, regardless of the illiquidity of the new opportunity. That's the entire point of this article.

To reiterate, all linear pricing techniques are appropriate for valuing illiquid corporate investments as long as maximization of shareholder wealth is taken as the goal of the firm. Our next objectives are to clarify the finance notion of valuation in the capital markets, to further illustrate that $D C F$ is an linear pricing technique (just like option pricing), and to demonstrate that tracking portfolios for use in linear pricing need not involve positions in the illiquid "underlying" asset. 


\section{Valuation in the Capital Markets}

A substantial amount of misunderstanding about option pricing arises because of the shortcuts we take when we teach the basics of $D C F$ valuation. Our goal in this section is to set the record straight on this matter. In order to do this, we'll have to proceed in the textbook fashion, point out the shortcuts along the way, and then re-proffer the model in a more complete form. We will use some numerical examples to help make our point.

The standard textbook approach is to present a one-period economy in which individuals can trade current consumption for future consumption. This setup, originally presented in Fisher $(1907,1930)$, is used to motivate both risk-adjusted discounting and the notion that firms should behave like investors (Fisher's "separation" result).

\section{A. The Green Acres Economy}

Let's consider the simplest possible model of risk. The community of Hooterville is a hamlet of $N$ individuals who are identical in preferences, tastes, endowments and beliefs about the future. The residents of Hooterville are farmers, and because of the geography of the local area, the only crop is corn. Furthermore, the people of Hooterville are completely isolated from the outside world. Hence, the only consumptive commodity is corn; the residents can consume only what they produce, no more and no less.

To keep things simple, suppose that the Hooterville economy lasts only one year, and at the end of the year the individuals share equally in the (random) output of the year's crop. In other words, all $\mathrm{N}$ individuals have identical contingent claims on the crop at the end of the year: 200 bushels of corn if there is a banner crop $\left(y_{\text {banner }}=200\right)$ but only 80 bushels if the crop is poor $\left(y_{\text {poor }}=80\right)$. Moreover, all of the individuals agree that 'banner' and 'poor' harvests are equally likely: $\pi_{\text {banner }}=\pi_{\text {poor }}=0.5$.

Each individual is endowed with 100 bushels of 'present' corn ( $y_{0}$ $=100$ ). Hooterville is a pure-exchange economy, so it is impossible for the residents to change their endowments by planting more/less or storing; however, they can change their consumption patterns by trading. Trading takes place at Sam Drucker's general store. Drucker's market allows the residents to alter their consumption across time: those 
wishing to consume more than 100 bushels of corn today may sell their future corn endowment, while those with extra corn today may purchase more future corn.

We reiterate that Hooterville is a pure-exchange economy - there is no investment and storage is not allowed (that is, the corn is perishable). So the total current crop (100 bushels of corn times $N$ individuals $=$ $100 \mathrm{~N}$ bushels) must be consumed today. Similarly, the entire future crop, whatever it may be, must be consumed at the end of the period.

The expected crop is $0.5 \times 200$ bushels $+0.5 \times 80$ bushels $=140$ bushels per person, times $N$ individuals $=140 \mathrm{~N}$ bushels. Individuals may trade current consumption for claims on future consumption so that some individuals may consume more than their endowments today while others consume less, but across the entire economy the consumption today must be $100 \mathrm{~N}$ bushels, and the expected consumption at the end of the year must be $140 \mathrm{~N}$ bushels (total consumption will be $200 \mathrm{~N}$ bushels of corn if the 'banner' crop appears and $80 \mathrm{~N}$ bushels if the 'poor' crop appears, regardless of the trades made).

Finally, we raise one caveat. In the following examples, we will derive a financial market equilibrium and then use the equilibrium prices of securities to price new trades between the Hooterville residents. Technically, the economy's linear pricing rule will correctly value only marginal trades and not large ones. The trades we will evaluate will represent large fractions of each individual's endowment. We take this very common shortcut for ease of presentation, and we thank an anonymous referee for stressing the importance of this issue.

\section{B. The 'Textbook' Presentation - The World of Certainty}

Virtually every Corporate Finance textbook begins with a chapter (often skipped by instructors), which demonstrates that individuals can use financial markets like Drucker's store to adjust their patterns of consumption over time. The ultimate point of such a chapter is to show that financial markets can provide a benchmark for investment decisions, and this in turn serves as the introduction to discounted cash flow and the $N P V$ rule.

For the sake of pedagogy, textbook authors take a shortcut: the intertemporal model with risk (where the future crop is uncertain, as described above) is simplified into a world of certainty (the future crop 
is known). This simplified sort of presentation works well to provide a motivation for the $N P V$ rule, but the insight about $N P V$ gained through the simplification comes at a pedagogical cost: it becomes much more difficult to explain to students what it means for projects to have different risks. Moreover, in a world of certainty there are no options - and the certainty leads many of us (the authors included) to make option pricing appear to be quite different from $D C F$.

In Hooterville, the shortcut changes the problem from one where the future harvest could be banner or poor to one where the certain crop is used as a substitute. In other words, any distinction between the welfare of the population in the banner-crop state and in the poor-crop state is completely lost. This turns out to be extremely important, because risk is really a function of how payoffs differ across different macroeconomic states. ${ }^{7}$

So instead of the future crop being random, we take the shortcut assumption that the future crop will be 140 . We maintain the assumption about current endowments, and specify that utility of consumption is given by

$$
U=\ln \left(c_{0} \cdot c_{1}\right)=\ln c_{0}+\ln c_{1}
$$

It is easy to derive the equilibrium price that must arise at Drucker's market for the single market exchange: every 1 additional bushel of corn in the future costs 0.714 bushels of corn today. To put it another way, one bushel of present corn will bring 1.40 bushels of future corn in exchange. Individuals who wish to give up present consumption can give up one bushel of corn today and get back 1.40 in the future; individuals who wish to consume against future wealth can get 1 additional bushel of corn today by sacrificing 1.40 bushels in the future. $^{8}$

The typical corporate finance textbook uses the following graphical depiction of the intertermporal consumption opportunities available through trading at Drucker's market.

7. For example, a 100-bushel loan to a resident of Hooterville differs in risk from a 20-bushel loan, because the small loan could always be repaid from future crop whereas the large loan defaults in the poor-crop state. The standard textbook treatment provides no distinction between the two because the future is collapsed to one state (a crop of 140); thus, both loans are incorrectly treated as having the same risk.

8. The derivation of the pure exchange equilibrium is given in the appendix. 


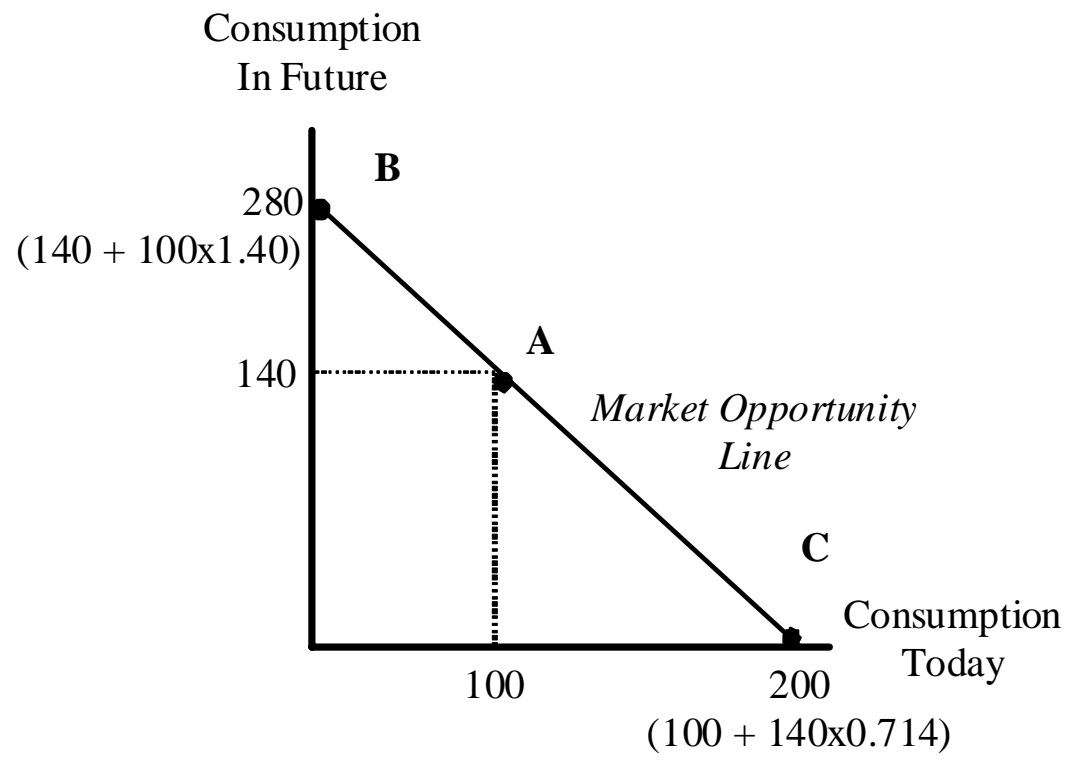

\section{FIGURE 2.}

In figure above, the point $\mathrm{A}$ is the initial endowment of Alf Monroe, a representative resident of Hooterville who (in partnership with his sister Ralph) provides carpentry services as a hobby. The horizontal axis presents Alf's current consumption of corn, and the vertical axis measures his future consumption of corn. The line that connects the two axes is the market opportunity line which represents all of the possible baskets of current and future consumption that Alf could achieve by trading in the market at Sam Drucker's; the slope of the market opportunity line represents, in equilibrium, how much current corn the residents of Hooterville are willing to give up in order to get one additional unit of future corn.

Point B on the chart represents the maximum amount of corn Alf could consume in the future by selling away (or lending) all 100 bushels of his current endowment of corn at the market price (140 of future endowment plus $100 *(1.40)$ of return on the loan of the current endowment). Point $\mathrm{C}$ represents the maximum amount of corn Alf could consume immediately by buying against his future endowment (or borrowing), which is 100 bushels of current endowment plus $140 *(0.714)$ current price of future endowment. 
We stress the point that even though this is a pure-exchange economy, there is a market rate of interest. An interest rate is simply the price of consumption in a future period relative to the price of consumption in an earlier period. Here, the market rate of interest is the equilibrium marginal rate of substitution between consumption of corn today and in the future. So even though the residents of Hooterville can't save or invest, they can use Drucker's market to observe the equilibrium interest rate and to trade claims on future consumption for claims on current consumption. Mathematically, the equilibrium rate of corn interest in Hooterville is

$$
-1 \cdot(\text { slope of market opportunity line })=(1+\text { rate of return })
$$

so

$$
r_{\text {corn }}=40 \%
$$

Armed with this information, Alf can examine any other opportunities that might arise. For example, suppose that one afternoon, Alf's sister Ralph offers to sell to Alf exactly one-fourth of her future corn endowment in exchange for 35 bushels of Alf's current endowment.

Alf examines this opportunity in the following way. One-fourth of Ralph's future endowment is $0.25 * 140=35$, so if Alf takes the deal he must give up 35 bushels of corn today in exchange for 35 in the future. Alf can evaluate this deal in several ways.

First, Alf might evaluate the deal graphically. The figure below reproduces Alf's market opportunity line from above and superimposes his augmented endowment after taking Ralph's proposal (point $R$ ) as well as his augmented market opportunity line given that he takes Ralph's proposal.

Clearly, Ralph's deal makes Alf poorer. In terms of maximum possible current consumption, Ralph's deal makes Alf strictly worse off by 10 bushels of corn. In terms of maximum possible future consumption, Ralph's deal makes Alf strictly worse off by 14 bushels of corn. It should not be surprising that $14 / 1.40=10$.

A second way for Alf to analyze Ralph's deal would be to ask the question slightly differently. Suppose that Alf were to go to Drucker's market and find a way to replicate Ralph's deal by trading. Ralph's deal promises 35 in the future and costs 35 today. If Alf can buy 35 bushels of future corn at Drucker's, how much more or less than Ralph's price would it cost? 


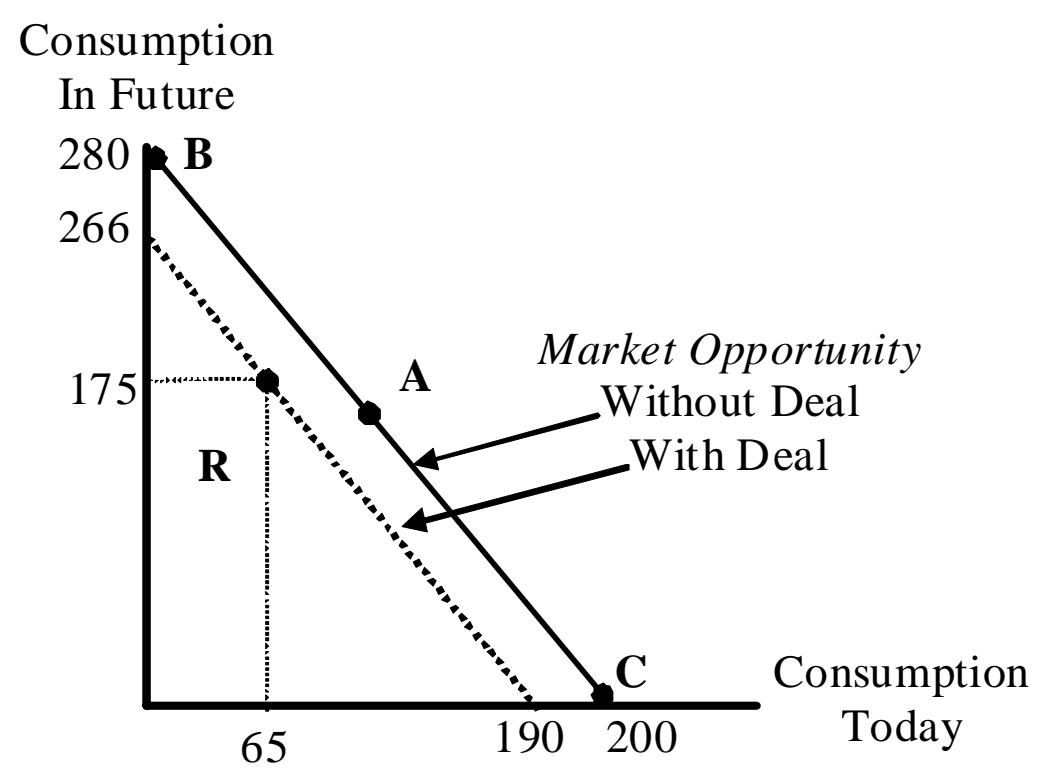

FIGURE 3.

At Drucker's, Alf can purchase 35 bushels of future corn at a price of 0.714 bushels of current corn each, or for a total price of $35 * 0.714$ $=25$. So, the same deal in the financial markets costs Alf 10 bushels of current corn less than the price Ralph is asking.

What this tells us is that the arbitrage-free price of Ralph's deal is 25 bushels of current corn. If Alf could sell the deal to Ralph instead of purchasing it, Alf could turn Ralph into a money pump. Of course, Alf himself becomes the money pump if he accepts the deal, because Ralph could immediately undo the deal at Drucker's and realize the arbitrage profit:

\begin{tabular}{|ccc|}
\hline Ralph's Payoffs & $\frac{\text { Today }}{35}$ & $\underline{\text { Future }}$ \\
Sell Deal to Alf & -35 \\
Buy 35 Bushels Future Corn at Drucker's @0.714 & -25 & 35 \\
Ralph's Arbitrage Profit & 10 & 0 \\
\hline
\end{tabular}


A third way for Alf to evaluate Ralph's proposal would be through a $D C F$ analysis (discounted corn flow), and application of the $N P V$ rule. Since the rate of return on corn in this market is $40 \%$, the present value of Ralph's promised future corn flow is

$$
P V(35 \text { bushels received in one year })=\frac{35}{1+r}=\frac{35}{1.40}=25
$$

Since the cost of entering Ralph's deal is 35 , then the NPV of Ralph's deal is

$$
\begin{aligned}
N P V(\text { Ralph's Deal }) & =P V(\text { Corn Inflows })-\text { Investment } \\
& =\frac{35}{1.40}-35=-10
\end{aligned}
$$

Two things should be noted here. First of all, the $N P V$ calculation gives us the exact wealth loss to Alf $(-10)$ that we calculated from both the graphical analysis as well as the arbitrage analysis. More importantly, perhaps, is the fact that the "present value of the corn inflows" calculation gave us a value of 25 - which is exactly equal to the arbitrage-free value of the future corn flows in the financial market. That is, the $P V$ of the inflows is the financial market price of those flows. Why is this? Because the $D C F$ analysis is actually an equivalent approach to linear pricing - the discount rate used is the rate of return that can be earned on the tracking that exactly mimics the new opportunity (like approach \#1 in the earlier section). In this case, the tracking portfolio that exactly mimics Ralph's deal is a long position in 35 bushels of future corn. Since the current price of this contract would be $35^{*}(0.714)=25$, the rate of return on the arbitrage portfolio is $(35 / 25$ $-1)=40 \%$ and discounting at $40 \%$ gives the arbitrage-free value of the deal. $D C F$ valuation is an application of linear pricing, and $N P V$ measures how much better or worse off the investor (Alf) becomes relative to buying the same deal in the financial markets.

\section{But Where Do Firms Fit In?}

Fisher $(1907,1930)$ extended the world of certainty to include production by firms. For example, the residents of Hooterville actually 
have a choice of what to do with this year's corn endowment: they can consume some of it, and they can plant the rest to change their endowment in the future. Fisher's very famous separation result states quite simply that in equilibrium, productive (or firm-level) decisions do not reflect any individual owner's time preferences, but instead simply act to push the market opportunity line to the right as far as possible. Why? Because the payoffs to production are returned to the individuals, and the individuals can exchange current and future consumption in the financial markets to achieve their own personal optima. Hence, Fisher's analysis requires that agents be free to trade their claims in the financial markets without friction.

This is the germinal analysis which gives a motivation for $D C F$, the $N P V$ rule, and the notion of shareholder value maximization. But we stress here that Fisher's analysis does not provide a normative rule for what managers should do when facing a new opportunity. Rather, it describes what happens in equilibrium (that is, the resulting prices and decisions of the cumulated agents in the economy). Application of the existing market prices (or rates of return) to new projects outside the equilibrium requires further assumptions - the analysis of which is the central point of the unanimity literature discussed above.

\section{When is $40 \%$ the Correct Discount Rate?}

Unfortunately, in Fisher's world of certainty $40 \%$ is the correct discount rate to use on any market opportunity. This is because the certainty-based presentation of the Hooterville economy allows for no introduction of risk, and hence all possible deals should be discounted at this rate. You'll frequently hear people say that "you can't price options via $D C F$ ". This is actually not true - the risk-adjusted rate of return on an option (at any given instant) is equal to the risk-adjusted rate of return on the tracking portfolio that prices the option. The problem with trying to value an option with $D C F$ is that there's no shortcut (e.g. CAPM) way to find the risk-adjusted discount rate without actually identifying the tracking portfolio. In option pricing, we have to use a different approach to linear pricing.

This suggests that there are two major drawbacks to the certainty presentation of the financial markets. The first is that it provides no way to teach a student the true economic meaning of the term risk. The second, which is related to the first, is that it misleads students about how/why tracking portfolios can be formed and how/why they price 
risk. In order to demonstrate these issues more clearly, we need to introduce uncertainty into the Fisher analysis.

\section{E. The More Complete Presentation of the Financial Market}

What we'll show now is that the deep intuition behind both $D C F$ and option pricing can only be achieved from the more precise (but more complex) multiple-state model of the financial market where risk is explicitly recognized. If we want to examine a new proposal in Hooterville whose payoff is truly risky, we have to introduce the notion of multiple possible states of nature (banner crop and poor crop) and keep track of them individually. Here we'll set up an equilibrium and derive the prices of current and future consumption across all future states. This analysis was developed in Debreu (1959); the presentation here follows Hirshleifer (1970).

We'll maintain the assumptions given earlier (in particular, that current endowment is 100 , the banner-state crop is 200, and the poor-state crop is 80 ). The one change we require is a new utility function, as we need to correctly capture that individuals are risk-averse across macroeconomic states. Let the utility of consumption function for every individual be

$$
U=\ln \left(c_{0} \cdot c_{\text {banner }}^{.5} \cdot c_{\text {poor }}^{.5}\right)=\ln c_{0}+0.5 \ln c_{\text {banner }}+0.5 \ln c_{\text {poor }}
$$

where $c_{0}, c_{\text {banner }}$ and $c_{\text {poor }}$ represent consumption in the present, banner and poor states (respectively). Equilibrium consumption choices will imply a set of market-clearing prices at which individuals may trade current corn for banner state corn and poor state corn (and to trade banner state corn for poor state corn).

We'll solve for prices by nominating present corn as the numeraire. Hence, each unit of 'present corn' has a price of $1\left(\varphi_{0}=1\right)$, and we want to solve for the price of corn in the banner state $\left(\varphi_{\text {banner }}\right)$ and poor state $\left(\varphi_{\text {poor }}\right)$ denominated in units of present corn. In the appendix, we derive the resulting pure-exchange equilibrium and show that $\varphi_{\text {banner }}=$ 0.25 and $\varphi_{\text {poor }}=0.625$. What this means is that every 1 extra bushel of corn consumption in the banner crop state costs 0.25 bushels of present corn consumption, while every 1 extra bushel of corn in the poor crop state costs 0.625 bushels of present corn. These are the prices of state-contingent claims. 
We pause here to make a very important statement about the term risk. The prices of consumption are different in the two states, even though the likelihood of the two states are identical, because aggregate consumption is different in the banner and poor crop states. Prices are determined in equilibrium by marginal utility, and if agents are risk-averse then marginal utility is high when consumption is low. Hence, the current price of consumption in the low-endowment state (the poor harvest) is substantially higher than the current price of consumption in the high-endowment state (the banner harvest). ${ }^{9}$

This observation illustrates the most basic economic notion of risk: to a consumer, the risk of a new proposal is measured by how the proposal pays off across future macroeconomic consumption states. If the new opportunity pays off well when aggregate consumption is high (but not when aggregate consumption is low), then it increases the individual's exposure to aggregate consumption risk and hence is risky and should be discounted severely. If, on the other hand, it pays off well when aggregate consumption is low (but not when it is high) then the new opportunity reduces the individual's exposure to aggregate consumption risk and hence is discounted at a low (or even negative) rate.

In the world with two possible future states, the graphical analysis has three dimensions: consumption today, consumption in the future given the banner-crop state, and consumption in the future given the poor-crop state.

The point $\mathrm{E}$ in the figure below represents the endowment of $\mathrm{Eb}$ Dawson - a simple but honest handyman; the plane illustrated by the dark black triangle represents Eb's market opportunity set. Eb wants to know his total wealth - that is, the total value of his current endowment plus the market value of his future, state-contingent endowment. How does Eb determine this amount? Well, he can simply go to the financial market at Drucker's and see how much others would pay today for his future corn in each crop state. Since the price of corn in the banner state is 0.25 , Eb could sell his banner-state corn for $200 * 0.25=50$ bushels of corn today; similarly, Eb could sell his poor-state corn for $80 * 0.625=$ 50 bushels of corn today. So the current (or present) value of Eb's future risky corn endowment is $50+50=100$ current bushels of corn.

"Gollygee", Eb declares to his scarecrow friend Stuffy, "My current

9. In lay terms, we're willing to pay more for insurance against being hungry than for insurance against being full. 


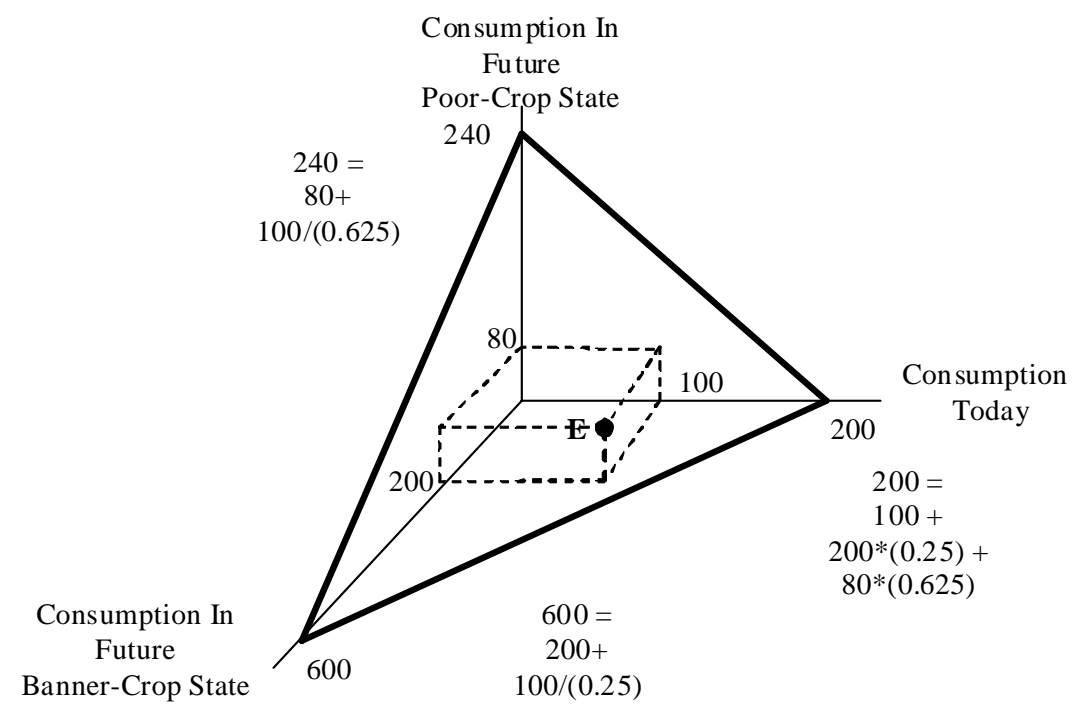

FIGURE 4.

TABLE 1.

\begin{tabular}{|c|c|c|c|}
\hline & \multirow[t]{2}{*}{ Today } & \multicolumn{2}{|c|}{ Future } \\
\hline & & 'Banner' State & 'Poor' State \\
\hline Eb's Original Endowment & 100 & 200 & 80 \\
\hline Sell Future 'Banner Crop' Endowment & 50 & -200 & \\
\hline Sell Future ‘Poor Crop’ Endowment & 50 & & -80 \\
\hline Eb's Current Wealth & 200 & 0 & 0 \\
\hline
\end{tabular}

wealth is 200 - I've got 100 bushels of corn in my crib, and my future corn is worth 100 on the market".

Notice that Eb's valuation is just another application of linear pricing. No matter what happens in the future, Eb's endowment has the same "corn flow" as a portfolio that is long 50 bushels of banner-crop corn and long 50 bushels of poor-crop corn:

Eb's Future Endowment $=50 \mathrm{x}(1$ bushel banner-crop corn $)+50 \mathrm{x}$ (1 bushel poor-crop corn)

Since there are no arbitrage opportunities at Drucker's, the current 
value of Eb's future endowment must be equal to the value of this tracking portfolio:

$$
\begin{aligned}
& \text { State }- \text { Price Value }(E d ' s \text { Future Endowment })= \\
& \qquad \begin{array}{c}
50 \times \phi_{\text {Banner }}+50 \times \phi_{\text {Poor }} \\
=50(0.25)+50(0.625) \\
=100
\end{array}
\end{aligned}
$$

We use the term state-price value to describe this particular representation of linear pricing because each security in the tracking portfolio is a state security. It is not at all essential that actual state securities trade at Drucker's; rather, they may be the shadow prices for consumption in each state which can be inferred from the market prices of bundles that include corn flow in both states.

This leads to a second point. Since Eb can find the current value of his future endowment of corn, then there must be an equilibrium discount rate for an investment in corn whose risk is exactly the same as the risk of Eb's endowment. Since the market value of Eb's future expected endowment is 100, and Eb's expected future endowment is $0.5 \times 200+0.5 \times 80=140$ bushels of corn, the equilibrium rate of interest (or pure rate of interest) is the $r_{\text {corn }}$ that solves

$$
\begin{aligned}
D C F \text { Value }(E d ' \text { 's Future Endowment }) & =100=\frac{0.5 \times 200+0.5 \times 80}{\left(1+r_{\text {corn }}\right)} \\
& =\frac{140}{\left(1+r_{\text {corn }}\right)} \quad \text { so } r_{\text {corn }}=40 \%
\end{aligned}
$$

In other words, the risky discount rate associated with the risk of the corn crop in this economy (which is the market rate of interest) is $40 \%$.

Eb can use this rate of return to calculate the $N P V$ of some new opportunities. Suppose Arnold Ziffle offers to pay Eb 105 bushels of corn today in exchange for Eb's entire allocation of corn, whatever it may be, in the future. From Eb's perspective, the future corn flows are 
TABLE 2.

\begin{tabular}{|c|c|c|c|}
\hline & \multirow[t]{2}{*}{ Today } & \multicolumn{2}{|c|}{ Future } \\
\hline & & 'Banner' State & 'Poor' State \\
\hline Eb's Original Endowment & 100 & 200 & 80 \\
\hline Sell Future Endowment to Arnold Ziffle & 105 & -200 & -80 \\
\hline Buy 200 bu 'Banner' state corn @.25/bu & -50 & 200 & \\
\hline Buy 80 bu 'Poor' state corn @.626/bu & -50 & & 80 \\
\hline Eb's New Wealth & 105 & 200 & 80 \\
\hline
\end{tabular}

negative and the current corn flow is positive, and $\mathrm{Eb}$ can calculate his $N P V$ from entering the deal as follows:

$$
\begin{aligned}
N P V(\text { Arnold Ziffle's Deal }) & =\frac{0.5(-200)+0.5(-80)}{1.40}+105 \\
& =-100+105 \\
& =5
\end{aligned}
$$

To show that the NPV is actually an arbitrage profit, note that Eb could enter this deal with Arnold and give up his entire future consumption, use the proceeds from the deal to repurchase his future risky endowment in the financial market, and come out wealthier:

From Eb's perspective, the arbitrage profit available from Arnold's proposal is 5. Note that this is exactly the $N P V$ calculated above. The $N P V$ is simply the arbitrage profit that can be earned by "buying low and selling high" between the financial asset market (Drucker's) and the real asset market (Arnold Ziffle's pigsty).

So now suppose an enterprising individual in Hooterville proposes a very unusual deal. Mr. Haney, an accomplished salesman, wants to sell all but 50 bushels of his future corn endowment, no matter what happens. In other words, he wants to assure himself 50 bushels for consumption in either future crop-state, but he's willing to turn over everything else (150 bushels in the banner crop state, or 30 bushels in the poor crop state) for 60 bushels of corn today. He approaches Oliver Wendell Douglass, the smartest man in Hooterville: "Mr. Douglass, this is your lucky day".

Mr. Douglass was prepared to evaluate the deal. While attending a 
TABLE 3.

\begin{tabular}{|c|c|c|c|}
\hline & \multirow[t]{2}{*}{ Today } & \multicolumn{2}{|c|}{ Future } \\
\hline & & 'Banner' State & 'Poor' State \\
\hline Mr. Haney's Original Endowment & 100 & 200 & 80 \\
\hline Sell all but 50 of future endowment to Douglas & 60 & -150 & -30 \\
\hline Buy 150 bushels 'Banner' state corn @.25/bu & -37.5 & 150 & \\
\hline Buy 30 bushels 'Poor' state corn @ .626/bu & -18.75 & & 30 \\
\hline Mr. Haney's New Wealth & 103.75 & 200 & 80 \\
\hline
\end{tabular}

prestigious eastern law school, Oliver took time to audit an introductory Finance course. He recalled from the very entertaining classes that one should discount any risky future corn flow using a required rate of return that is commensurate with corn risk. He explained his reasoning to his wife in the following way: "Lisa, since the discount rate implied by the current valuation of everyone's future risky corn crop is $40 \%$, then I must use $40 \%$ as the discount rate when purchasing risky claims on future corn." Mr. Douglas thus valued and evaluated the Haney deal as follows:

$$
\begin{aligned}
\text { NPV }(\text { Mr.Haney's Deal }) & \stackrel{?}{=} \frac{0.5(150)+0.5(30)}{1.40}-60 \\
& \stackrel{?}{=} 64.29-60 \\
& \stackrel{?}{=} 4.29
\end{aligned}
$$

"We're rich, Lisa. With this deal, we can turn that scoundrel Haney into a money pump. He thinks the deal is only worth 60 , when in fact it is worth 64.29." So Mr. Douglas entered the deal and paid Mr. Haney 60 bushels of corn. Mr. Haney then went straight to Drucker's market and bought back the future corn allotment he had just sold to $\mathrm{Mr}$. Douglas. See the table above.

Mr. Haney's wealth today increased by 3.75 while his future wealth remained the same. In other words, Mr. Haney became richer by exactly 3.75. But this is a zero-sum deal - whatever Mr. Haney makes, Mr. Douglas loses. So contrary to what Mr. Douglas believes, Mr. Haney has actually gotten the better end of this deal. The true value of the deal to Mr. Douglas is -3.75 , and not +4.29 . Where did Mr. Douglas 
make an error?

What Mr. Douglas didn't realize is that the deal he bought from Mr. Haney does not have the same risk as the overall corn market. The fact that Mr. Haney made money at Mr. Douglas' expense tells us that Mr. Douglas overvalued the deal - in other words, the discount rate that Mr. Douglas used was too low. How can this be true? What should have been the right discount rate?

To answer these questions, we need to start with an easier one: in what situations would it be correct for Mr. Douglas to use $40 \%$ as the discount rate on risky corn deals?

First, we've already established that $40 \%$ is the correct discount rate to use on the corn crop as a whole (i.e., on aggregate consumption). If Mr. Douglas prices his original future endowment using a $40 \%$ discount rate, there are no arbitrage profits available:

$$
D C F \text { Value }(\text { Endowment })=\frac{0.5(200)+0.5(80)}{1.40}=100
$$

$$
\text { State }- \text { Price Value }(\text { Endowment })=200 \cdot(0.25)+80 \cdot(0.625)=100
$$

Suppose Mr. Douglas were to sell one-half of his future endowment (100 bushels of corn in the banner crop state, and 40 in the poor crop state). Does a $40 \%$ discount rate work? The valuation of this risky corn deal using $D C F$ is

$$
\text { DCF Value }(\text { Mr.Douglas' Deal })=\frac{0.5(100)+0.5(40)}{1.40}=50
$$

and the value of an equivalent deal in at Drucker's market is

State - Price Value $($ Mr.Douglas' Deal $)=100 \cdot(0.25)+40 \cdot(0.625)$

$$
=50 \text {. }
$$

So $40 \%$ is the correct discount rate for this particular deal.

Now suppose the Bradley sisters (Billy Jo, Bobby Jo and Betty Jo) want to pool their future endowments and sell them to Uncle Joe (a total of 600 banner-state bushels and 240 poor-state bushels). Would the $40 \%$ 
TABLE 4.

\begin{tabular}{|c|c|c|c|c|c|}
\hline & \multicolumn{2}{|c|}{$\begin{array}{l}\text { State-Contingent } \\
\text { Deal Payoff }\end{array}$} & \multicolumn{2}{|c|}{$\begin{array}{c}\text { Bushels Required in } \\
\text { Tracking Portfolio }\end{array}$} & \multirow[t]{2}{*}{$\begin{array}{c}\text { Ratio } \\
\text { Banner:Pool }\end{array}$} \\
\hline & 'Banner' & 'Poor' & 'Banner' & 'Poor' & \\
\hline Eb's Endowment & 200 & 80 & 200 & 80 & $2.5: 1$ \\
\hline Bradley Sisters' Deal & 600 & 240 & 600 & 240 & $2.5: 1$ \\
\hline Mr. Douglas’ Deal & 100 & 40 & 100 & 40 & $2.5: 1$ \\
\hline Arnold Ziffle's Deal & -200 & -80 & -200 & -80 & $2.5: 1$ \\
\hline Mr. Haney’s Deal & 150 & 30 & 150 & 30 & $5.0: 1$ \\
\hline
\end{tabular}

discount rate give an arbitrage-proof price? The DCF valuation would be

$$
\begin{aligned}
\text { DCF Value }(\text { Bradley Sisters' Deal }) & =\frac{0.5(3 \times 200)+0.5(3 \times 80)}{1.40} \\
& =300 .
\end{aligned}
$$

One could re-create the same future corn flows at Drucker's market at a cost of

$$
\begin{gathered}
\text { State }- \text { Price Value }(\text { Bradley Sisters' Deal })^{\prime}=3 \times 200 \cdot(0.25)+3 \\
\times 80 \cdot(0.625)=300
\end{gathered}
$$

They are the same; hence the $D C F$ at $40 \%$ again gives the right answer.

The reason as to why $40 \%$ is the right discount rate on all of these deals is critical but subtle. Each of these deals can be re-created by trading, at Drucker's market, in the right quantities of banner-crop corn and poor crop corn. While the total quantities of each differ, there is one constant across all of these deals: the ratio of banner-state corn to poor state corn in the tracking portfolio is 2.5:1. The table above makes this clear.

"The" proper risk-adjusted discount rate for a new opportunity is the market's priced rate of return on the tracking portfolio that exactly mimics that opportunity. For any new opportunity $x$ that promises $x_{\text {banner }}$ bushels of corn in the banner state and $x_{\text {poor }}$ bushels of corn in the poor 
state, the proper tracking portfolio contains $x_{\text {banner }}$ bushels of banner state corn and $x_{\text {poor }}$ bushels of poor state corn, so the current price of the tracking portfolio (and the deal) is $P_{x}=x_{\text {banner }} \cdot \varphi_{\text {banner }}+x_{\text {poor }} \cdot \varphi_{\text {poor }}$. The expected future value of this tracking portfolio is $E\{x\}=\pi_{\text {banner }} \cdot x_{\text {banner }}$ $+\pi_{\text {poor }} \cdot x_{\text {poor }}$, and thus the expected return on the tracking portfolio is

$$
\frac{E\{x\}-P_{x}}{P_{x}}=\frac{\pi_{\text {banner }} \cdot x_{\text {banner }}+\pi_{\text {poor }} \cdot x_{\text {poor }}}{x_{\text {banner }} \cdot \phi_{\text {banner }}+x_{\text {poor }} \cdot \phi_{\text {poor }}}-1=r_{x}
$$

This expected return is the risk-adjusted discount rate for pricing the new opportunity $x$ by standard $D C F$ pricing

$$
P_{x}=\frac{\pi_{\text {banner }} \cdot x_{\text {banner }}+\pi_{\text {poor }} \cdot x_{\text {poor }}}{1+r_{x}}
$$

and it is easy to show that $r_{x}$ is the same for all deals where the ratio $x_{\text {banner }} / x_{\text {poor }}$ is the same. In our example, when the ratio $x_{\text {banner }} / x_{\text {poor }}=$ 2.5 , the correct discount rate to use to value the opportunity is $40 \%{ }^{10}$

Mr. Douglas mispriced the Haney deal because the discount rate he used was not appropriate: the discount rate Mr. Douglas used was appropriate for risks that mimic the risk of the overall economy, and the Haney deal has a completely different risk profile (as shown by the 5:1 ratio of its banner-to-poor corn holdings in its arbitrage portfolio). But we still have not ascertained the right discount rate for the Haney deal. This takes a little more work, and a little more in the way of general results.

To give the simplest illustration of a deal whose ratio of cash flows across states is not equal to the ratio of aggregate consumption across states, consider Hank Kimball, the county agent. Mr. Kimball is quite conservative, and he is looking to buy a deal that will deliver him 15 bushels of corn in the future no matter what the crop turns out to be. The future corn flows on this deal are obviously risk-free, but there is no risk-free asset available in Hooterville. $40 \%$ is clearly not the right discount rate. But what is?

There's no way to know without explicitly forming the tracking $=2.5$.

10. Notice that 2.5 is the inverse of the state price ratio: $\varphi_{\text {poor }} / \varphi_{\text {banner }}=0.625 / 0.25$ 
portfolio first. This is the general problem with valuation of derivatives and assets with derivative-like payoffs (like forward contracts and like Mr. Haney's deal): $D C F$ would work if you know the correct discount rate, but there is no way to know the right discount rate without knowing the tracking portfolio (and hence the value of the derivative) in the first place. To value derivatives, we have to rely on a different approach to linear pricing - we create a portfolio of existing claims from the financial markets that exactly replicate the payoff on the derivative; the value of that package of claims is the value of the derivative. If that sounds to you like the way we described $D C F$ above, then you are paying attention. $D C F$ and option pricing methodology are built on the same foundation - linear pricing in an arbitrage-free financial market - and hence rely on the same underlying assumptions - no arbitrage opportunities in financial markets (and, if we are applying the $N P V$ rule inside a firm, price-taking by managers).

The financial market price of the deal Mr. Kimball desires is 13.125. This can be seen through the simple exercise of buying 15 bushels of banner-state corn at 0.25 each and 15 bushels of poor-state corn at 0.625 each:

State - Price Value $($ Mr. Kimball's Deal $)=15 \cdot(0.25)+15 \cdot(0.625)$

$$
=13.125
$$

This is the arbitrage-free price of the risk-free claim. Hence, we can derive the correct discount rate to use on deals proportional to $\mathrm{Mr}$. Kimball's:

$$
\begin{aligned}
D C F \text { Value }(M r . \text { Kimball's Deal }) & =\frac{0.5(15)+0.5(15)}{\left(1+r_{\text {Kimball }}\right)}=\frac{15}{1+r_{F}} \\
& =13.125 \text { so } \quad r_{F}=14.3 \%
\end{aligned}
$$

The appropriate discount rate for Mr. Kimball's deal, as well as any other deal where the ratio of banner-state payoff to poor-state payoff is $1: 1$, is $14.3 \%$. This is because the expected return on the tracking portfolio that exactly mimics this deal is $14.3 \%$.

So this takes us back to Mr. Haney's deal. Remember, Mr. Haney 
offered Mr. Douglas 150 banner-state bushels of corn and 30 poor-state bushels of corn. Mr. Haney's deal is a derivative; it is actually a European call option on his entire future endowment with strike price equal to 50. The payoff on this deal is not invariant to the future state, so the risk-free rate is not the appropriate discount rate. Moreover, these payments are not proportional to aggregate consumption, so $40 \%$ is not the correct discount rate. So what is the correct discount rate to use to value Mr. Haney's deal?

Mr. Haney's deal can be replicated in the financial markets by buying 150 bushels of banner-state corn at a cost of $0.25 /$ bushel, and 30 bushels of poor-state corn at a cost of $0.625 /$ bushel. So the present value of Mr. Haney's deal (the price which gives it a zero NPV) is

$$
\begin{aligned}
\text { State }- \text { Price Value }(\text { Mr. Haney's Deal }) & =150 \cdot(0.25)+30 \cdot(0.625) \\
& =37.5+18.75=56.25
\end{aligned}
$$

If the deal can be purchased for less than this, the purchaser has found a positive $N P V$ opportunity. Mr. Douglas, on the other hand, paid 60 for the deal - a negative $N P V$ investment!

Now that we know the value of Mr. Haney's deal, we can calculate the discount rate that would have given us the correct answer:

$$
\begin{aligned}
D C F \text { Value }(\text { Mr. Haney's Deal }) & =\frac{0.5(150)+0.5(30)}{1+r_{M r . \text { Haney }}} \\
& =56.25 \text { so } r_{M r . \text { Haney }}=60 \%
\end{aligned}
$$

The right discount rate to use on Mr. Haney's deal is $60 \%$ - much higher than the pure rate of interest on corn. This correct discount rate provides Mr. Douglas' true NPV from entering Mr. Haney's Deal:

$$
\begin{aligned}
N P V(M r . \text { Haney's Deal @ 60\% }) & =\frac{0.5(150)+0.5(30)}{1.60}-60 \\
& =56.25-60=-3.75
\end{aligned}
$$

which shows that the value destruction caused to Mr. Douglas by 
entering Mr. Haney's deal is exactly the same as Mr. Haney's arbitrage profits from selling (shorting) the deal.

You might be wondering why the discount rate on Mr. Haney's deal is so high. This is a standard result in finance: Mr. Haney's deal is a call option on his future corn endowment (with a strike price of 50), and call options are always riskier than the underlying asset on which they are written. This is often explained to students as a leverage effect, because the hedge portfolio that mimics the option is a levered position in the underlying asset. But the story is much deeper.

To see why derivatives have different risk from their underlying assets in general, it is necessary to look at two very special derivatives. The "Banner Crop Special" pays off 1 bushel of corn in the banner crop state and nothing in the poor crop state, while the "Poor Crop Special" pays off 1 bushel of corn in the poor crop state and nothing in the banner crop state. ${ }^{11}$

State - Price Value $($ Banner Crop Special $)=0.25(1)+0.625(0)$

$$
=0.25
$$

$$
\begin{aligned}
\text { DCF Value (Banner Crop Special }) & =\frac{0.5(1)+0.5(0)}{1+r_{\text {Banner }}} \\
& =0.25 \text { so } r_{\text {Banner }}=100 \%
\end{aligned}
$$

State - Price Value $($ Poor Crop Special $)=0.25(0)+0.625(1)$

$$
=0.625
$$

$$
\begin{aligned}
\text { DCF Value }(\text { Poor Crop Special }) & =\frac{0.5(0)+0.5(1)}{1+r_{\text {Poor }}} \\
& =0.625 \text { so } r_{\text {Poor }}=-20 \%
\end{aligned}
$$

11. The "Banner State Special" is a call on someone's future endowment at a strike price of 199, while the "Poor State Special" is a put on the same endowment with a strike price of 81. 


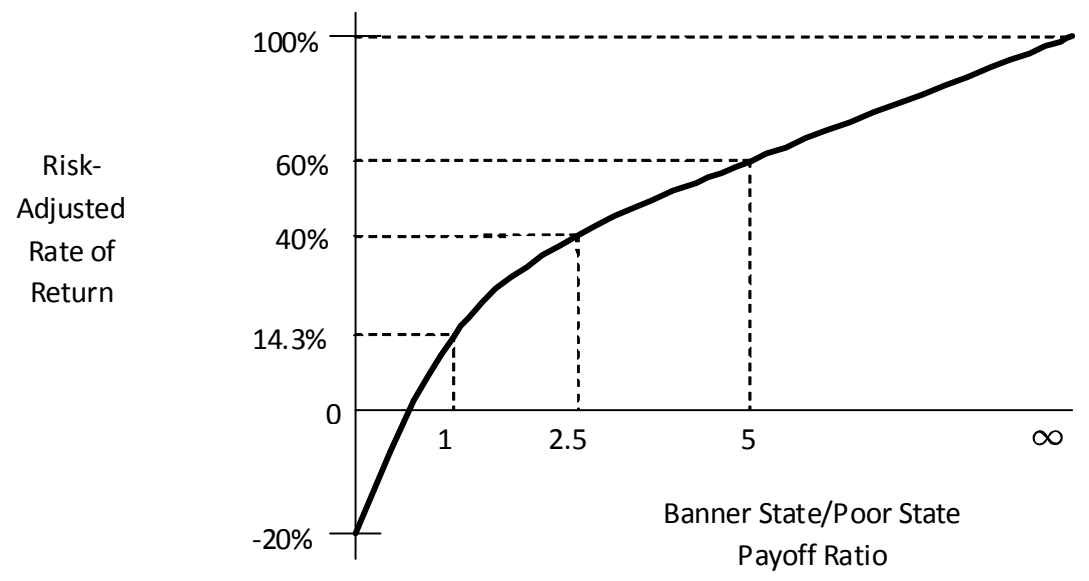

FIGURE 5.

The participants at Drucker's market impose a very high discount rate on the Banner Crop Special, and a negative discount rate on the Poor Crop Special. Why? One of the important results from microeconomics is that marginal utility of consumption is highest when total consumption is lowest. In other words, people value an additional unit of consumption in the low-endowment state (the poor crop state) much more highly than they do in the high-endowment state (the banner crop state), so when markets open at Drucker's, the price of the Poor Crop Special comes out higher than the price of the Banner Crop Special even though they have the exact same expected payoff ( 0.5 bushels of future corn). ${ }^{12}$ In this economy, people value consumption in the poor crop state so much that the price of the Poor Crop Special is above its expected payoff (and hence is being discounted at a negative discount rate). The Poor Crop Special is actually an insurance contract that insures the buyer against the poor consumption state, and the fact that risk-averse people are willing to pay a price higher than expected value for an insurance contract is the economic reason that the insurance industry exists.

Note what else this means: each future state of nature has its own

12. This is not a trick. As long as aggregate consumption is different across the two states, risk-averse individuals in the economy will wish to hedge against the low-consumption state and will value consumption in such a way that, in equilibrium, $\varphi_{\text {banner }} / \pi_{\text {banner }}<\varphi_{\text {poor }} /$ $\pi_{\text {poor }}$ (or, in technical terms, the pricing kernel or state-price density is decreasing in consumption). 
unique discount rate. When the ratio of payoffs across states for a new deal is equal to the ratio of aggregate consumption across states, then the aggregated discount rate of $40 \%$ is appropriate; however, when flows from a deal are more heavily weighted towards one of the states, then the market-wide rate of $40 \%$ is not appropriate. The figure above shows how discount rates change as the ratio of banner-state payoff to poor-state payoff varies.

This is the real reason that call options (like the Haney deal) are priced at such a high discount rate - their payoffs are realized in high-discount rate states. In other words, they increase the individual's exposure to aggregate consumption risk, and hence are considered very risky.

\section{F. A More Familiar Approach: Risk-Neutral Probabilities}

At this point, you may be questioning our interpretation of options in the simple economy and you might think that textbook approaches to option valuation won't get the same answers. We'll show that this is not the case. The familiar binomial option pricing model of Cox, Ross and Rubenstein (1979), which gives the famous Black-Scholes (1973) model in the limit as time steps become small and the number of steps become large, gives the exact same results that we've just derived.

The Hooterville economy is easy to place in a binomial framework. Just let aggregate consumption be the nodes of the binomial tree above.

The percentage change in consumption in the banner crop state (i.e. the size of the 'up' step in the binomial model) is $(200 \mathrm{~N} / 100 \mathrm{~N})-1=$ $+100 \%$; similarly, the percentage change in consumption in the poor crop state (i.e. the size of the 'down' step in the binomial model) is $(80 N / 100 N)-1=-20 \%$. Remembering that the risk-free payoff can be achieved by buying Mr. Kimball's deal above, and that the market price of this deal implied a risk-free rate of return of $14.3 \%$, we can calculate the familiar risk-neutral probability for this economy:

$$
q=\frac{r-d}{u-d}=\frac{0.143-(-0.20)}{1.00-(-0.20)}=0.286
$$

The risk-neutral probability $q$, along with the risk-free discount rate, prices all assets (including derivatives) in this economy using the risk-neutral probability approach to linear pricing (here in the form of 


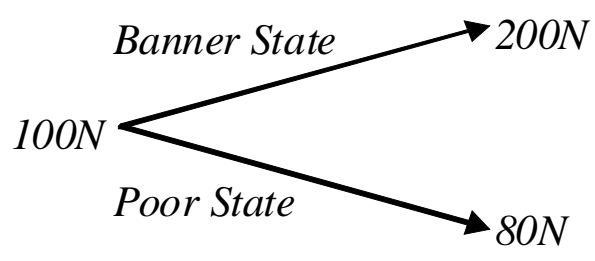

$$
+100 \%
$$

FIGURE 6.

the binomial model):

$$
\begin{gathered}
\text { Risk }- \text { Netural Probability Value }= \\
\frac{q \cdot(\text { payoff in banner state })+(1-q)(\text { payoff in poor state })}{1+r_{F}}
\end{gathered}
$$

For example, Eb Dawson's Future Endowment:

$$
\begin{aligned}
& \text { Risk }- \text { Netural Probability Value }(E d ' s \text { Future Endowment })= \\
& \qquad \frac{0.286(200)+0.714(80)}{1.143}=100
\end{aligned}
$$

which is the exact answer we got before. Or, Mr. Haney's Deal:

$$
\begin{gathered}
\text { Risk }- \text { Netural Probability Value }(\text { Mr. Haney's Deal })= \\
\frac{0.286(150)+0.714(30)}{1.143}=56.25
\end{gathered}
$$

again, precisely the same answer as before. The risk-neutral pricing model will price any asset in the economy properly. The reason is direct: risk-neutral probabilities are simply an alternative (but 
equivalent) expression of the linear pricing result. If the financial market allows no arbitrage opportunities, then there exists a set of risk-neutral probabilities such that the risk-neutral pricing model (i.e., expected future cash flows calculated using the risk-neutral probabilities and then discounted at the risk-free rate of return) prices all assets in the economy.

To see the equivalence, note that we can re-arrange the risk-neutral probability model valuation equation and get something very similar:

$$
\begin{gathered}
\text { Risk }- \text { Netural Probability Value }= \\
\frac{q}{1+r_{F}}(\text { Payoff in Banner State })+\frac{1-q}{1+r_{F}}(\text { Payoff in Poor State })
\end{gathered}
$$

Using Mr. Haney's deal again as the example:

$$
\begin{aligned}
& \text { Risk }- \text { Netural Probability Value }(\text { Mr. Haney's Deal })= \\
& \frac{0.286}{1.143}(150)+\frac{0.714}{1.143}(30)=0.25(150)+0.625(30)=56.25
\end{aligned}
$$

The similarity between the state-price valuation of Mr. Haney's deal and the risk-neutral probability valuation of the same deal should strike you, because

$$
\frac{q}{1+r_{F}}=\phi_{\text {Banner }} \quad \text { and } \quad \frac{1-q}{1+r_{F}}=\phi_{\text {poor }}
$$

(check for yourself!). The famous risk-neutral probabilities from option pricing (the $N\left(d_{2}\right)$ terms in the Black-Scholes model) are actually prices for state securities scaled by the risk-free return factor: $q=\left(1+r_{F}\right) \varphi_{B a n n e r}$, and $1-q=\left(1+r_{F}\right) \varphi_{\text {Poor }}$.

\section{G. Yet Another Approach to Linear Pricing}

As we just discussed, the state price representation of the linear pricing result in Hooterville is 


$$
\begin{gathered}
\text { State }- \text { Price Value }=\phi_{\text {Banner }} \cdot(\text { Payoff in Banner State }) \\
+\phi_{\text {Poor }}(\text { Payoff in Poor State })
\end{gathered}
$$

If we define two new quantities $\rho_{\text {banner }}$ and $\rho_{\text {poor }}$ as follows:

$$
\rho_{\text {banner }}=\frac{\phi_{\text {banner }}}{\pi_{\text {banner }}} \text { and } \rho_{\text {poor }}=\frac{\phi_{\text {poor }}}{\pi_{\text {poor }}}
$$

and then substitute these new quantities into the state price representation of the linear pricing rule, we get what is known as the state price density representation of the linear pricing rule:

$$
\begin{aligned}
\text { State }- \text { Price Density Value } & =\pi_{\text {banner }} \rho_{\text {banner }} c_{\text {banner }}+\pi_{\text {poor }} \rho_{\text {poor }} c_{\text {poor }} \\
& =E\{\rho c\}
\end{aligned}
$$

$\rho$ is often called the pricing kernel or state price deflator, and it measures priced scarcity of consumption. Its existence in an arbitrage-free financial market is derived via a mathematical result known as the Riesz Representation Theorem, and so this linear pricing approach is sometimes referred to as a Riesz Representation.

A proof that each of the linear pricing representations is both necessary and sufficient for the others can be found in Dybvig and Ross (2003).

\section{A Note About Complete Markets}

There is substantial misunderstanding about the term complete markets. The first misunderstanding involves what states need to be hedged. The true requirement is that, for every possible aggregate consumption state, there exists some portfolio or portfolio strategy that pays off exactly one if that state occurs and exactly zero otherwise. This does not mean that there needs to be a way to hedge against any future contingency - the only contingencies that need to be hedged for markets to be complete are states that are defined by aggregate consumption (because those are the only risks that are priced).

It is important to note here that firm-specific, idiosyncratic outcomes 
do not constitute states of nature. The systematic portion of an asset's risk is described by the asset's expected payoff in each macroeconomic state; potential deviations from these expected payoffs in each state are idiosyncratic and thus diversifiable. If every macroeconomic aggregate consumption state can be identified with a state security, then the systematic risk of any new opportunity can be exactly replicated with the state securities. Perfect tracking is not essential for valuation of any sort ( $D C F$, option pricing, or whatever) - all we need is for our tracking portfolio to have an expected error of zero in each possible macroeconomic state of nature.

The second misunderstanding is the widespread belief that there needs to be a single traded security for every possible future consumption state. This is not true. All that is needed is a way to create state securities (see Ross, 1976), and trading in primary securities allows markets to be complete. So when intertemporal trading is allowed, the number of securities needed to complete the market can be very small. In fact, Duffie and Huang (1985) show that if aggregate consumption follows a geometric Brownian motion process, then the market can be completed by trading in a grand total of two securities.

This turns out to be the reason that people insist on assuming that the underlying asset be tradable in order to price options - because the tradability assumption is actually equivalent to a market completeness assumption. If we assume that the underlying asset and a risk-free bond are continuously tradable, then over any very short time interval a binomial model exists and the market is necessarily complete (two states, two assets). So as perverse as it sounds, many people reject the market completeness assumption - and then proceed to make it anyway through the tradability assumption.

\section{Summary and Conclusion}

First, maximization of shareholder value (defined as using financial market prices to determine values of new opportunities via the financial market's linear pricing rule) is the appropriate goal of management if and only if,

(1) The financial markets are free of arbitrage opportunities, and

(2) Managers act as price takers, which requires that

(a) The financial markets are sufficiently complete, 
(b) The new investment does not affect aggregate consumption in a material way.

Second, if these conditions are met, valuation of corporate opportunities using any representation of the market's linear pricing rule (whether it be $D C F$, a tracking portfolio approach, or any of the others) are equally valid: absence of arbitrage alone assures that a linear pricing rule exists, and price taking assumes that the cash flows from any new corporate asset are linearly related to the cash flows on existing securities.

We'd like to put it one final way. $D C F$ analysis of an illiquid new capital investment is an application of linear pricing, and it requires that there exists a liquid portfolio of financial market securities which exactly mimics the state-contingent distribution of cash flows on the illiquid project. So if there is a liquid portfolio of traded securities that mimics the project, then one can value options on that liquid portfolio. Of course, options on that portfolio can be constructed to exactly mimic options on the illiquid project, so it is entirely appropriate to value options on the illiquid project even though the project itself can't be held in an arbitrage portfolio. Why? Because the tracking portfolio can be found in the liquid capital markets.

And that brings us full circle. Maximization of shareholder value is applicable only when markets are arbitrage free and managers are price takers, and when these conditions are met then managers can use option pricing to value new propositions in the same way (and for the same reasons) that they can use $D C F$. And thus the point of this paper: if you are willing to make the assumptions necessary to perform a $D C F$ analysis on an illiquid new corporate investment and let $N P V$ be the decision rule for managers, you have already made all the assumptions necessary for application of option pricing techniques to corporate investments.

Accepted by: Prof. L. Trigeorgis, Guest Editor, April 2007

Prof. P. Theodossiou, Editor-in-Chief, April 2007

\section{Appendix: Derivation of the Pure-Exchange Equilibria}

\section{A. Equilibrium Prices in the World of Certainty}

The consumer's optimization problem is 


$$
\begin{gathered}
\max _{\left\{c_{0}, c_{1}\right\}} U\left(c_{0}, c_{1}\right) \\
\text { s.t. } \quad c_{0}+\phi_{1} c_{1}=y_{0}+\phi_{1} y_{1}
\end{gathered}
$$

From the Lagrangian

$$
l=U\left(c_{0}, c_{1}\right)-\lambda\left(c_{0}+\phi_{1} c_{1}-y_{0}-\phi_{1} y_{1}\right)
$$

the first-order conditions are

$$
\begin{gathered}
\frac{\partial l}{\partial c_{0}}=\frac{\partial U}{\partial c_{0}}-\lambda=0 \\
\frac{\partial l}{\partial c_{1}}=\frac{\partial U}{\partial c_{1}}-\lambda \phi_{1}=0
\end{gathered}
$$

Clearing the Lagrangian multiplier,

$$
\frac{\partial c_{1}}{\partial c_{0}}=\frac{1}{\phi_{1}}
$$

Taking the total differential of the utility function

$$
d U=\frac{\partial U}{\partial c_{0}} d c_{0}+\frac{\partial U}{\partial c_{1}} d c_{1}
$$

so along any utility isoquant (where $d U=0$ )

$$
\left.\frac{d c_{1}}{d c_{0}}\right|_{U}=-\frac{\partial U / \partial c_{0}}{\partial U / \partial c_{1}}
$$

Evaluating the terms,

$$
\frac{\partial U}{\partial c_{0}}=\frac{1}{c_{0}}
$$




$$
\frac{\partial U}{\partial c_{1}}=\frac{1}{c_{1}}
$$

so

$$
\left.\frac{d c_{1}}{d c_{0}}\right|_{U}=-\frac{\partial U / \partial c_{0}}{\partial U / \partial c_{1}}=-\frac{c_{1}}{c_{0}}
$$

Additionally,

$$
\left.\frac{d c_{1}}{d c_{0}}\right|_{U}=-\frac{\partial U / \partial c_{0}}{\partial U / \partial c_{1}}=-\frac{\partial c_{1}}{\partial c_{0}}=-\frac{1}{\phi_{1}}
$$

so

$$
-\frac{c_{1}}{c_{0}}=\frac{1}{\phi_{1}} \quad \text { or } \quad \phi_{1}=\frac{c_{0}}{c_{1}}
$$

Since it is a pure-exchange economy, individuals must hold their endowments in equilibrium so

$$
\phi_{1}=\frac{100}{140}=0.714
$$

\section{B. Equilibrium Prices in the World of Uncertainty}

The consumer's optimization problem is

$$
\max _{\left\{c_{0}, c_{\text {banner }}, c_{\text {poor }}\right\}} U\left(c_{0}, c_{\text {banner }}, c_{\text {poor }}\right)
$$

s.t. $\quad c_{0}+\phi_{\text {banner }} c_{\text {banner }}+\phi_{\text {poor }} c_{\text {poor }}=y_{0}+\phi_{\text {banner }} y_{\text {banner }}+\phi_{\text {poor }} y_{\text {poor }}$

From the Lagrangian

$$
\begin{gathered}
l=U\left(c_{0}, c_{\text {banner }}, c_{\text {poor }}\right)-\lambda\left(c_{0}+\phi_{\text {banner }} c_{\text {banner }}+\phi_{\text {poor }} c_{\text {poor }}-y_{0}\right. \\
\left.-\phi_{\text {banner }} y_{\text {banner }}-\phi_{\text {poor }} y_{\text {poor }}\right)
\end{gathered}
$$

the first-order conditions are 


$$
\begin{gathered}
\frac{\partial l}{\partial c_{0}}=\frac{\partial U}{\partial c_{0}}-\lambda=0 \\
\frac{\partial l}{\partial c_{\text {banner }}}=\frac{\partial U}{\partial c_{\text {banner }}}-\lambda \phi_{\text {banner }}=0 \\
\frac{\partial l}{\partial c_{\text {poor }}}=\frac{\partial U}{\partial c_{\text {poor }}}-\lambda \phi_{\text {poor }}=0 .
\end{gathered}
$$

Along the isoutility curve,

$$
\begin{gathered}
\frac{\partial c_{\text {banner }}}{\partial c_{0}}=-\frac{1}{\phi_{\text {banner }}} \\
\frac{\partial c_{\text {poor }}}{\partial c_{0}}=-\frac{1}{\phi_{\text {poor }}}
\end{gathered}
$$

In our problem,

$$
\begin{gathered}
\frac{\partial U}{\partial c_{0}}=\frac{1}{c_{0}} \\
\frac{\partial U}{\partial c_{\text {banner }}}=\frac{0.5}{c_{\text {banner }}} \\
\frac{\partial U}{\partial c_{\text {poor }}}=\frac{0.5}{c_{\text {poor }}}, \text { so } \\
-\frac{\partial U / \partial c_{0}}{\phi_{\text {banner }}}=\left.\frac{\partial c_{\text {banner }}}{\partial c_{0}}\right|_{U}=-\left.\frac{1 / c_{0}}{\partial U / \partial c_{\text {banner }}}\right|_{U}=-\left.\frac{c_{\text {banner }}}{0.5 c_{0}}\right|_{U} \\
-\frac{1}{\phi_{\text {poor }}}=\left.\frac{\partial c_{\text {poor }}}{\partial c_{0}}\right|_{U}=-\left.\frac{\partial U / \partial c_{0}}{\partial U / \partial c_{\text {poon }}}\right|_{U}=-\left.\frac{1 / c_{0}}{0.5 / c_{\text {poor }}}\right|_{U}=-\left.\frac{c_{\text {poor }}}{0.5 c_{0}}\right|_{U}
\end{gathered}
$$

Since all of the individuals have identical beliefs, preferences, endowments and productive opportunities (none), the corn market must 
establish a set of prices such that each individual is satisfied to hold his or her original endowment. Evaluating the above at $c_{0}=y_{0} ; c_{\text {banner }}=$ $y_{\text {banner }} ; c_{\text {poor }}=y_{\text {poor }}$, we find the equilibrium prices

$$
\begin{gathered}
-\frac{1}{\phi_{\text {banner }}}=-\left.\frac{c_{\text {banner }}}{0.5 c_{0}}\right|_{U}=-\left.\frac{y_{\text {banner }}}{0.5 y_{0}}\right|_{U}=-\frac{200}{0.5(100)}=-4 \text { so } \phi_{\text {banner }}=0.25 \\
-\frac{1}{\phi_{\text {poor }}}=-\left.\frac{c_{\text {poor }}}{0.5 c_{0}}\right|_{U}=-\left.\frac{y_{\text {poor }}}{0.5 y_{0}}\right|_{U}=-\frac{80}{0.5(100)}=-1.6 \text { so } \phi_{\text {poor }}=0.625 .
\end{gathered}
$$

\section{References}

Black, F., and Scholes, M. 1973. The Pricing of Options and Corporate Liabilities", Journal of Political Economy 81, 637-659.

Cox, J.; Ross, S.; and Rubenstein, M. 1979. Option Pricing: A Simplified Approach". Journal of Financial Economics 34, 1092-1110.

Debreu, G. 1959. The Theory of Value, John Wiley \& Sons.

Duffie, D., and Huang, C. F. 1985. Implementing Arrow-Debreu Equilibria By Continuous Trading of Few Long-Lived Securities". Econometrica 53, 1337- 1356.

Dybvig, P. H., and Ross, S. A. 1987. Arbitrage". The New Palgrave: A Dictionary of Economics. Macmillan, London.

Dybvig, P. H., and Ross, S. A. 2003. Arbitrage, State Prices and Portfolio Theory", in Handbook of the Economics of Finance, George Constantinides, Milton Harris and Rene Stulz, ed., Elsevier North-Holland, 2003.

Fisher, I. 1907. The Rate of Interest, The Macmillan Company.

Fisher, I. 1930. The Theory of Interest, The Macmillan Company.

Grossman, S. J., and Hart, O. D. 1979. A Theory of Competitive Equilibrium in Stock Market Economies". Econometrica 47, No. 2.

Hirshleifer, J. 1970. Investment, Interest and Capital, Prentice-Hall, Inc.

Ross, S. A. 1976. Options and Efficiency", Quarterly Journal of Economics 90, No. 1, 75-89.

Baron, D. P. 1979a. Investment Policy, Optimality, and the Mean-Variance Model, Journal of Finance 34, No. 1, 207-232.

Baron, D. P. 1979b. On The Relationship Between Complete and Incomplete Financial Market Models, International Economic Review 20, No. 1, 105-117.

Ekern, S., and Wilson, R. 1974. On the Theory of the Firm in an Economy with Incomplete Markets. Bell Journal of Economics 5. 
Fama, E. F. 1972. Perfect Competition and Optimal Production Decisions Under Uncertainty. Bell Journal of Economics 3.

Fama, E. F. 1978. The Effects of a Firm's Investment and Financing Decisions. American Economic Review 68.

Grossman, S. J., and Stiglitz, J. E. 1977. On Value Maximization and Alternative Objectives of the Firm. Journal of Finance 32, 389-402.

Harrison, M., and Kreps, D. 1979. Martingales and Multiperiod Securities Markets, Journal of Economic Theory 20, 381-408.

Jensen, M. C., and Long Jr., J. B. 1972. Corporate Investment Under Uncertainty and Pareto Optimality in the Capital Markets. Bell Journal of Economics 3.

Leland, H. E. 1974. Production Theory and the Stock Market. Bell Journal of Economics 5.

Pye, G. 1966. Present Values for Imperfect Capital Markets. Journal of Business 39.

Radner, R. 1974. A Note on Unanimity of Stockholders' Preferences Among Alternative Production Plans: A Reformulation of the Ekern-Wilson Model. Bell Journal of Economics 5.

Ross, S. A. 1987a. Finance, The New Palgrave: A Dictionary of Economics, Macmillan.

Ross, S. A. 1987b. The Interrelations of Finance and Economics: Theoretical Perspectives. Journal of Finance 77, No. 2, 29-34.

Summers, L. H. 1985. On Economics and Finance, Journal of Finance 40 No. $3,633-635$. 